\title{
REPOSITÓRIO INSTITUCIONAL COMO ALTERNATIVA À GESTÃO DA PRODUÇÃO INTELECTUAL DA UNIVERSIDADE FEDERAL DE PELOTAS - UFPEL
}

\author{
INSTITUTIONAL REPOSITORY AS AN ALTERNATIVE FOR THE MANAGEMENT OF \\ INTELLECTUAL PRODUCTION OF THE FEDERAL UNIVERSITY OF PELOTAS - UFPeI
}

\section{Catarina de Quevedo Prestes de Carvalho ${ }^{1}$ Rodrigo Aquino de Carvalho ${ }^{2}$}

\begin{abstract}
RESUMO: Este estudo fundamenta-se na necessidade da Universidade Federal de Pelotas de identificar uma nova forma de gestão da sua produção intelectual e no fato da Instituição ter sido contemplada pelo Instituto Brasileiro de Informação em Ciência e Tecnologia com um kit tecnológico para construção e desenvolvimento de um repositório institucional. A pesquisa buscou verificar a adequação do repositório institucional às necessidades constatadas pela Equipe responsável pela gestão da informação na Universidade, através de dois instrumentos: um questionário aplicado a um dos integrantes da Equipe responsável pela implantação dessa solução, e um formulário (elaborado com base nos tópicos suscitados a partir do questionário respondido) aplicado na análise da obra Como gerenciar e ampliar a visibilidade da informação científica brasileira: repositórios institucionais de acesso aberto. O resultado da análise demonstra viabilidade na utilização do repositório como plataforma para a gestão da produção científica da Universidade Federal de Pelotas.
\end{abstract}

PALAVRAS-ChAVE: Universidade Federal de Pelotas. Repositório Institucional. Produção Intelectual Institucional.

ABSTRACT: This study is based on the Federal University of Pelotas' necessity to identify a new formof managementof its intellectual production, andin the fact that the Institution has been contemplated with a technological kit by the Brazilian Institute of Information in Science and Technology, to construct and develop an institutional repository.The research sought to verify the adequacy of the institutional repository towards the necessities identified by the Team responsible for the management of information at the University, through two instruments: a questionnaire applied to one of the members of the Team responsible for the implementation of this solution, and a form (based on the topics raised from the answered questionnaire) applied on the analysis of the work How to manage and broaden the visibility of Brazilian scientific information: open access institutional repositories. The results of analysis showed feasibility of using the repository as a platform for the scientific production management of the Federal University of Pelotas.

KEYWORDS: Federal University of Pelotas. Institutional Repository. Intellectual Institutional Production.

\footnotetext{
${ }^{1}$ Bibliotecária da Faculdade de Direito da UFPel. Graduada em Biblioteconomia pela Universidade Federal do Rio Grande do Sul - UFRGS (2010), Especialista em Gestão de Projetos pela Anhanguera Educacional (2012), Aluna especial do mestrado em Memória Social e Patrimônio Cultural da Universidade Federal de Pelotas (PPGMP-UFPel). Pelotas-RS-Brasil. E-mail: catarinaprestes@yahoo.com.br.

${ }^{2}$ Professor Assistente do curso de Biblioteconomia da Universidade Federal do Rio Grande - FURG. Bacharel em Biblioteconomia e Mestre em Ciência da Informação de PUC-Campinas. Campinas-SPBrasil. E-Mail: $\underline{\text { racfurg@gmail.com }}$

Recebido em: 29/07/2013 - Aceito em: 04/02/2014
} 


\section{INTRODUÇÃ̃o}

Frente às mudanças impostas pela era da informação e conhecimento, que suscitam maior agilidade e transparência nos processos da comunicação científica, as instituições de ensino e pesquisa têm buscado alternativas para manter a confiabilidade das informações produzidas, otimizando o tempo necessário para conclusão do ciclo de produção da informação. Essas instituições têm buscado também ampliar o acesso à informação por parte da comunidade interessada, além de atentarem para a preservação digital de seu patrimônio intelectual. Nesse sentido, uma opção bastante em voga no meio acadêmico e científico, em vários países do mundo, é o Repositório Institucional (RI).

O Instituto Brasileiro de Informação em Ciência e Tecnologia (IBICT) lançou edital disponibilizando kits tecnológicos ${ }^{3}$ (composto de um servidor pré-formatado e configurado com sistema operacional baseado na plataforma Unix/Linux e softwares, como o Apache, MySQL e PHP, Eprints, Dspace e SEER) a instituições públicas de ensino e pesquisa, visando promover o desenvolvimento e a utilização de RI por parte dessas.

A Universidade Federal de Pelotas (UFPel), que também obteve um kit do IBICT, carece de uma solução para reunir, organizar e disponibilizar a produção intelectual de seus pesquisadores na Web. Entretanto, faz-se necessário avaliar se um RI satisfaz plenamente as necessidades de gestão e disponibilização da produção intelectual institucional. Dessa forma, o presente estudo teve como objetivo verificar a adequação do RI às necessidades da UFPel, no que diz respeito à gestão da sua produção intelectual.

\section{COMUNICAÇÃO CIENTÍFICA EM TEMPOS DE ACESSO ABERTO}

A comunicação científica sempre exerceu um papel norteador, em muitos aspectos, dos processos de gestão da informação e do conhecimento.-Como elucida Leite (2008, p. 7): "Processos de comunicação científica permitem o acesso,

\footnotetext{
${ }^{3}$ EDITAL DE CHAMADA FINEP/PCAL/XBDB No 002/2009. Disponível em: $<$ http://www.in.gov.br/visualiza/index.jsp?jornal=3\&pagina=187\&data=17/04/2009>. Acesso em: 12 jul. 2013.
} 
organização, preservação, compartilhamento, disseminação, uso e reuso do conhecimento produzido". Sendo assim, pode-se perceber que o ato de comunicar é indissociável das atividades científicas, tendo em vista que descobertas ocorrem sempre a partir dos conhecimentos acumulados, processados, adequadamente registrados e divulgados.

A comunicação científica, a partir da Internet maximizou possibilidades e mudou significativamente a forma de comunicar e acessar os resultados de pesquisa. Diante dessas questões a comunidade científica realizou alguns eventos, produzindo declarações e convenções que resultaram na Iniciativa dos Arquivos Abertos, no Acesso Aberto, no autoarquivamento e, abarcando tudo isso, nos repositórios. Como registram Moraes e Marcondes (2006):

\begin{abstract}
Seguiram-se eventos, registrando o desejo da comunidade científica de mudança do processo editorial da comunicação na ciência, dentre os quais se destacam: a Declaraçãodo Movimento de Acesso Livre de Budapest; a Declaração de Bethesda e a Declaração de Berlin, chamadas por Rodrigues ${ }^{4}$ de 'Declarações de Independência' porque consolidaram as diretrizes operacionais para o funcionamento da publicação científica em Arquivos Abertos. (MORAES; MARCONDES, 2006, p. 6).
\end{abstract}

Eis o contexto de surgimento dos repositórios digitais, como forma de divulgar a produção científica, prezando pela transparência e livre acesso aos resultados. No entanto, cabe se salientar que a publicação em repositórios de arquivos abertos e de livre acesso não tem o intuito de substituir a publicação em periódicos, como ressalta Ginsparg (2000) apud Triska e Café (2001) ${ }^{5}$ :

Os arquivos de textos eletrônicos são inteiramente dirigidos pelos cientistas e são flexíveis o bastante tanto para coexistir com os sistemas de publicação tradicional como para ajudar estes sistemas para se desenvolverem como algo mais próximo das necessidades dos pesquisadores. (TRISKA; CAFÉ, 2001, p. 93).

Para o melhor entendimento dos processos relacionados ao modo de funcionamento dos repositórios, fazem-se necessários alguns esclarecimentos acerca de dois termos: Arquivos Abertos e Acesso Aberto. O conceito de Arquivos Abertos (Open Archives), bem como as recomendações iniciais a respeito do tema, tem como marco a

\footnotetext{
${ }^{4}$ RODRIGUES, Eloy. Acesso livre ao conhecimento: a mudança do sistema de comunicação da ciência e os profissionais de informação. Cadernos BAD: Rede de Comunicação em Bibliotecas e Arquivos, Lisboa, n. 1, p. 24-35, 2004. p. 28. apud MORAES; MARCONDES, 2006, p. 6.

${ }^{5}$ GINSPARG, Paul. Creating a global knowledge network. In: FREEDOM OF INFORMATION CONFERENCE: the impact os open access on biomedical research, 2000, New York Academy of Medicine, BioMed Central. New York, 2000 apud TRISKA; CAFÉ, 2001, p. 93.
} 
Convenção de Santa Fé, realizada em outubro de 1999 no Novo México. Os Arquivos Abertos têm seu conceito formado a partir dos termos aberto - no sentido da disponibilidade de informações, no tocante a sua existência, natureza e localização - e arquivo - referindo-se ao armazenamento dos conteúdos em meio eletrônico, ou seja, aos recursos serem depositados (estarem disponíveis) na Web. Às vezes ocorre certa confusão quanto ao termo "aberto", ligando-o ao sentido de livre ou gratuito. No entanto, nesse caso, nada tem a ver com o acesso gratuito à informação, pois após a localização da informação na Web, pode-se constatar que o repositório onde a mesma está depositada requer uma contrapartida financeira, ou mesmo, impõe alguma restrição de uso.

A confusão se deve em parte a outro termo composto também pela palavra "aberto", relacionado ao acesso de documentos online. Trata-se do termo Acesso Aberto (Open Acess). Nessa perspectiva o termo refere-se à acessibilidade irrestrita a conteúdos disponíveis em formato digital, removendo barreiras de preço e de permissão, tornando a literatura científica disponível com o mínimo de restrições de uso (COSTA, 2006). Ou seja, consiste no acesso livre aos documentos através da Web. Para ser considerada uma publicação de livre acesso, Kuramoto (2006) ressalta dois requisitos: a autorização, por parte do detentor dos direitos autorais, concedendo acesso livre a todos os usuários e; o depósito em um RI da versão integral do trabalho, em formato eletrônico, devidamente padronizado, acompanhada do termo de permissão.

A Iniciativa dos Arquivos Abertos apóia-se em algumas ferramentas e procedimentos fundamentais, são eles, segundo Weitzel (2005): o autoarquivamento; conjunto de metadados padronizados para descrição; livre acesso à produção cientifica; e o protocolo para coleta de metadados (Open Archives Initiative Protocol for Metadata Harvesting - OAI-PMH), que busca tornar comunicáveis diferentes arquivos. OAIPMH surgiu com o objetivo de operacionalizar a coleta de metadados, independente dos aplicativos - computadores, programas e tecnologias - utilizados.

A OAI propõe ainda a padronização das comunicações através da troca de solicitações e de metadados entre um provedor de dados (na fase inicial eram exclusivamente repositórios e-print, depois ampliados para todos os conteúdos digitais de natureza acadêmica) e um provedor de serviços externo, fazendo uso de robôs coletores de dados. Conforme esclarece Marcondes e Sayão (2002): 
Dentro da concepção OAI, existem as instituições chamadas provedoras de dados (Data Providers), que são bancos de documentos eletrônicos que oferecem facilidades para publicação e armazenamento de documentos eletrônicos e sua disponibilização em um servidor conectado à Internet, e as instituições provedoras de serviços (Service Providers), que coletam metadados de um ou mais provedores de serviço e com estes metadados prestam serviços de valor agregado. (MARCONDES; SAYÃO, 2002, p. 4748).

Portanto, o arquivo aberto fornece metadados para serem coletados e disponibilizados por outros provedores. O OAI-PMH é, segundo Pavani (2005) ${ }^{6}$ : “[...] uma maneira convencionada de recolher, de forma automatizada, metadados de arquivos abertos (que abrem seus metadados mas não necessariamente os seus conteúdos)." Possibilitando a transferência de metadados de um sistema para outro, independentemente das tecnologias e produtos utilizados para implementar os sistemas.

Os metadados expostos pelos provedores de dados e coletados pelos provedores de serviços devem, por sua vez, obedecer a um padrão. O padrão mais utilizado pelos mecanismos de coleta é o Dublin Core (DC) não qualificado, porém esse padrão pode sofrer adaptações conforme o interesse, desde que se esteja utilizando o protocolo da OAI para que os repositórios possam interoperar. Kuramoto (2006, p. 96) ressalta que: “O estabelecimento do protocolo OAI-PMH e a definição de um padrão de metadados possibilitam estabelecer um alto nível de interoperabilidade entre os repositórios digitais [...]". O OAI-PMH foi feito para suportar qualquer padrão de metadados que pode ser representado em Extensible Markup Language - XML, entretanto ele estabelece que um repositório deva ter, no mínimo, suporte para Dublin Core não qualificado (THE OPEN..., 2008).

Com conseqüência dessa facilidade, diversos softwares foram desenvolvidos utilizando o modelo da OAI. Sendo assim, é possível afirmar que o repositório, atentando a todos esses padrões que possibilitam a interoperabilidade e o livre acesso às informações nele arquivadas, constitui-se como um novo viés da comunicação científica. Maiores esclarecimentos sobre os RI, sua forma de operação e suas funcionalidades são fornecidas a seguir.

\footnotetext{
${ }^{6}$ Documento retirado da Internet, sem paginação.
} 


\subsection{Repositório Institucional}

Quando se fala de repositórios disponíveis na Web tem sido adotada a nomenclatura repositório digital (RD), visando distingui-lo dos repositórios em papel, como por exemplo, os utilizados na área jurídica ${ }^{7}$. Os RD funcionam como provedores de dados destinados ao gerenciamento da informação científica. Segundo Viana, Márdero Arellano e Shintaku (2005, p. 3): “Um repositório digital é uma forma de armazenamento de objetos digitais que tem a capacidade de manter e gerenciar material por longos períodos de tempo e prover o acesso apropriado." Os RD subdividem-se de acordo com sua aplicação, seus fins e a ferramentas tecnológicas empregadas no seu desenvolvimento. Embora haja algumas variações no tocante a subdivisão dos RD, a que esteve mais presente na literatura da área é a descrita por Viana e Márdero Arellano (2006), a qual elenca apenas duas categorias de RD: repositório temático - RT, que cobre uma determinada área do conhecimento; e repositório institucional - RI, que é uma forma de gestão documental que busca preservar o conhecimento gerado pela instituição, além de disponibilizá-lo à comunidade. Constitui-se o último, objeto do presente estudo, sendo assim, a partir de agora, as considerações serão exclusivamente sobre RI.

Os RI são, segundo Lynch (2003, tradução nossa) ${ }^{8}$, “[...] um conjunto de serviços que a instituição oferece aos seus membros para o gerenciamento e disseminação de materiais digitais criados na instituição". Na mesma linha, Crow (2002, tradução nossa) ${ }^{9}$ define repositório institucional como: “[...] um arquivo digital de produtos intelectuais criados por uma comunidade de pesquisadores, estudantes e professores de uma instituição". Seu conteúdo costuma ser: trabalhos de cunho acadêmico e científico provenientes de atividades de pesquisa e ensino, bem como, documentos variados derivados de atividades das universidades. (VIANA; MÁRDERO ARELLANO; SHINTAKU, 2005).

De simples implementação, os RI requerem somente, segundo Viana e Márdero Arellano (2006, p. 3): “[...] uma estrutura hierarquizada, acesso via web e metadados

\footnotetext{
${ }^{7}$ Repositórios autorizados de legislação e jurisprudência, dos quais se valem os tribunais para dar valor legal as publicações deste gênero.

${ }^{8}$ Documento retirado da Internet, sem paginação.

${ }^{9}$ Documento retirado da Internet, sem paginação.
} 
coletados através do protocolo OAI-PMH, permitindo assim que os usuários, ao usarem qualquer mecanismo de busca da Iniciativa dos Arquivos Abertos, possam encontrar e recuperar o conteúdo do repositório".

Por ser em essência um meio de autopublicação, os RI necessitam tão somente de promoção institucional para que sejam utilizados. Basta, portanto, que as instituições reconheçam e valorizarem os documentos depositados nos RI e estabeleçam as ligações entre a informação que precisam e a que desejam disponibilizar para se formar uma rede de publicação gerenciada por pesquisadores e suas instituições, com projeção nacional e internacional (LEITE, 2008). No tocante ao acesso à informação científica os RI desempenham ainda outra função - a preservação digital. Sua validade no processo de preservação se dá na medida em que propiciam maior segurança aos conteúdos digitais depositados, através do constante gerenciamento das mudanças tecnológicas ocorridas.

Pode-se dizer que os RI visam, essencialmente, o melhoramento do processo de comunicação científica. Para tanto, provêm os mecanismos que aumentam tanto a eficácia da preservação da produção intelectual de pesquisadores e instituições acadêmicas, quanto sua visibilidade. Crow (2002) declara que os RI além de expandir o acesso à informação gerada a partir de pesquisas, reafirmam o controle da academia sobre o saber.-Entre as principais finalidades dos RI, estão de acordo com Leite (2008):

\begin{abstract}
Gerenciar informação científica proveniente das atividades de pesquisa e ensino, e oferecer suporte a elas; melhorar a comunicação científica interna e externa à instituição; maximizar o uso, a visibilidade e o impacto da produção científica da instituição por meio da maximização do acesso a ela; retroalimentar a atividade de pesquisa científica e apoiar os processos de ensino e aprendizagem; preservar o acesso; preservar os conteúdos digitais científicos ou acadêmicos produzidos pela instituição ou seus membros; contribuir para o aumento do prestígio da instituição e do pesquisador; oferecer insumo para a avaliação e monitoramento da produção científica; reunir, armazenar, organizar, preservar, recuperar e disseminar a produção científica da instituição. (LEITE, 2008, p. 38).
\end{abstract}

A implantação de RI pode ocorrer de forma simples, pois apresenta poucos requisitos para sua construção, contudo requer um software que respeite alguns princípios e padrões. O DSpace é adequado à criação de RI e atenta a princípios da Iniciativa dos Arquivos Abertos (OAI), como interoperabilidade e autoarquivamento. Tendo em vista que o software disponibilizado no kit fornecido pelo IBICT à UFPel foi 
o DSpace, este trabalho se aterá ao fornecimento de maiores informações a respeito desse.

O DSpace é um software gratuito. Foi desenvolvido pelo Massachusetts Institute of Technology (MIT) e pelos Laboratórios Hewlett-Packard (HP), objetivando a criação de RI e bibliotecas digitais para centros de pesquisa. Seu diferencial é ser estruturado em comunidades e coleções. Dessa maneira, sua configuração expõe e deixa claro o conjunto de unidades administrativas que constituem determinada instituição. Sua plataforma comporta diversos formatos de arquivos digitais, sejam eles texto, imagem ou som. Possibilita ainda a revisão por pares, através de uma configuração semelhante à utilizada no processo editorial dos periódicos tradicionais.

No entanto, existem questões que excedem a programação inicial dos softwares, necessitando definição durante o projeto do RI, tais como:

a) aperfeiçoamento das tarefas de alimentação, no tocante as suas funcionalidades;

b) estabelecimento de políticas específicas para melhorar o desempenho do repositório;

c) análise da relação custo $\mathrm{x}$ benefício antes de qualquer iniciativa que implique no acréscimo de funções, customizações ou alterações na configuração padrão do software, atentando especialmente a aspectos tecnológicos, inclusive quanto à obtenção de recursos humanos especializados em sistemas;

d) realização de um levantamento dos gastos envolvidos na adoção de um destes softwares, além de um prognóstico dos gastos prováveis que estes acarretarão anualmente à instituição;

e) observação da amplitude organizacional, ou seja, do porte da instituição (quantidade de institutos que compõem sua estrutura) no momento da opção por determinada arquitetura para o desenvolvimento do RI.

Tais questões excedem as delimitações que um software genérico pode oferecer, pois requerem definições por parte da instituição responsável pelo repositório, caracterizando-se mais como uma atividade de gestão, que ultrapassa os limites previsíveis por um software projetado para construção de repositórios em geral, que não leva em conta as especificidades de cada instituição.

Sendo assim, após o esclarecimento sobre questões intrínsecas ao surgimento e funcionamento dos RI, pode-se passar a parte metodológica desse estudo. 


\section{METODOLOGIA}

Para fins de consecução do presente trabalho realizou-se uma pesquisa exploratória, adotando como procedimento de coleta de dados o estudo de caso, devido à possibilidade de ampliação ou detalhamento de um objeto específico, proporcionada por esse tipo de procedimento. O sujeito da pesquisa foi o Comitê Gestor da Produção Intelectual da UFPel - representado por um bibliotecário que compõe o Comitê, que respondeu em nome desse.

No tocante as fontes de informação, a pesquisa se caracterizou como de campo, pois foi aplicado um questionário ao bibliotecário do Comitê Gestor, estabelecendo-se contato direto com o objeto estudado. Por outro lado, a pesquisa também foi classificada como bibliográfica, pois a partir do formulário, elaborado com base nas necessidades de gestão da informação da UFPel, foi feita a análise de uma obra nacional publicada pelo IBICT que descreve as características dos RI de acesso aberto, o que possibilitou chegar a etapa final do presente trabalho.

\subsection{Instrumentos de Coleta de Dados}

Quanto à natureza dos dados, tratava-se de uma pesquisa qualitativa, pois a obtenção dos dados se deu através da aplicação de um questionário - ao bibliotecário mencionado - e da análise, via formulário, de uma obra bem específica, mencionada nesta seção e constante nas referências do artigo. O tratamento dos dados se deu de forma analítica, a partir da comparação das informações obtidas via questionário, com os dados levantados através do formulário, buscando responder aos questionamentos que motivaram a formulação do objetivo deste trabalho.

O questionário foi encaminhado ao membro do Comitê encarregado pelo desenvolvimento e promoção do RI da UFPel, ou de solução equivalente, no que diz respeito à gestão das informações produzidas no âmbito da Universidade. O bibliotecário recebeu o questionário após contato presencial, durante o qual aceitou colaborar com a pesquisa e devolver o questionário respondido dentro de duas semanas. Esse instrumento buscou conhecer as necessidades vislumbradas pela Equipe, a qual possui integrantes que já vêm coordenando outros projetos de gestão da informação na 
UFPel. Entretanto, tendo em vista que o levantamento das necessidades e as decisões tomadas partiram de reuniões do Comitê Gestor, considerou-se redundante aplicar o questionário a cada um de seus integrantes, sendo por esse motivo, aplicado apenas um questionário - ao bibliotecário já mencionado.

A construção do questionário, que contava com doze questões, sete abertas e quatro de múltipla escolha, deu-se a partir de diálogos com alguns membros do Comitê Gestor, além da análise de políticas de funcionamento de RI de outras universidades federais brasileiras. Alguns questionamentos foram suscitados a partir dessas duas fontes de informação, possibilitando a elaboração do instrumento baseado em pontos chave, que refletiam as necessidades e dúvidas do Comitê. Esse instrumento, devidamente respondido, serviu de guia para a construção do formulário utilizado na análise da Obra, pois tornou evidentes as informações imprescindíveis para apoiar o processo decisório da Equipe responsável pela Gestão da Informação, sobre a adequação do RI as suas necessidades.

O questionário (APÊNDICE A) continha questão referentes a três áreas temáticas: aspectos gerenciais (oito questionamentos); aspectos técnicos (dois questionamentos) e; aspectos relacionados ao conteúdo do RI (apenas um questionamento). A maior parte desse instrumento se referia a aspectos gerenciais, pois esses englobam desde decisões políticas da Universidade, sobre o fluxo operacional do RI, até questões concernentes à finalidade e ao funcionamento dos repositórios.

O formulário (APÊNDICE B), cujos tópicos pautaram-se nas necessidades levantadas com a aplicação do questionário, foi estruturado em dez pontos, sete deles com enfoque técnico e três com enfoque administrativo. Embora se tenha dado maior atenção aos aspectos técnicos, não foram desprestigiadas as características intrínsecas à proposta dos RI, no que tange à forma de gestão. Seu modo de disponibilizar, disseminar e comunicar o conteúdo nele arquivado também foi observado através do formulário.

A partir do formulário realizou-se a análise da obra - Como gerenciar e ampliar a visibilidade da informação científica brasileira: repositórios institucionais de acesso aberto - uma publicação IBICT, com autoria de Fernando César Lima Leite. Devidamente expostos os instrumentos desta pesquisa, a próxima seção dedica-se a apresentação da Instituição que foi objeto desse estudo. 


\subsection{Caracterização da Instituição Objeto do Estudo}

A UFPel é uma instituição de ensino superior, mantida pela União. Possui campi universitários nas cidades de Pelotas e Capão do Leão, somando cerca de (99) noventa e nove cursos de graduação e (72) setenta e dois cursos de pós-graduação, sendo (15) quinze programas de mestrado e doutorado, (17) de mestrado, (3) três de mestrado profissional, (28) vinte e oito de especialização e (9) nove de residência médica (UNIVERSIDADE..., 2012).

A Instituição completa em agosto 44 anos de existência. No princípio contava apenas com as Faculdades de Ciências Domésticas, Veterinária (Universidade Federal Rural do Rio Grande do Sul), Direito, Odontologia e o Instituto de Sociologia e Política, além da tradicional Faculdade de Agronomia Eliseu Maciel (FAEM) - a mais antiga do Brasil (UNIVERSIDADE FEDERAL DE PELOTAS, 1999). Em dezembro do mesmo ano a UFPel passou a contar também com os Institutos de Biologia, de Ciências Humanas, de Química e Geociências, de Física e Matemática e Instituto de Artes. Hoje sua estrutura acadêmica encontra-se significantemente modificada, devido à criação de cursos e unidades, bem como a incorporação, extinção e transformação dessas.

\section{ANÁLISE DOS RESULTADOS}

No processo de identificação das necessidades e anseios doComitê Gestor da Produção Intelectual da UFPel, utilizou-se o questionário (APÊNDICE A). Já na segunda fase desta pesquisa elaborou-se um formulário (APÊNDICE B) que amparou o processo de verificação quanto à adequação da plataforma de RI fornecida pelo IBICT, através do kit tecnológico, às necessidades identificadas.

A análise dos dados se deu na mesma ordem de realização da pesquisa, ou seja, começando pelo questionário. Para melhor elucidar as informações obtidas através das respostas, essas foram expostas em grupos, de acordo com seu aspecto predominante. 


\subsection{Questionário}

Os questionamentos de um a cinco, oito, nove e doze, que tratavam de aspectos gerenciais, evidenciaram que a UFPel necessita de uma solução para gestão de sua produção intelectual que: dê maior visibilidade à informação científica produzida por esses; constitua-se como forma de preservação digital desse conteúdo; possibilite a inserção colaborativa e descentralizada desses conteúdos, mas com gestão centralizada pelo Comitê Gestor; seja efetivamente um base de dados que concentre toda a produção intelectual da Instituição, mesmo que por um período alguns documentos não possam ser visualizados, por motivo de embargo; atenda aos objetivos de reunião, disseminação e gestão de toda a informação produzida no âmbito da UFPel.

O desejo expresso pela Equipe de não só disponibilizar, mas de ampliar o acesso de forma irrestrita aos resultados das pesquisas desenvolvidas no âmbito da Universidade, denotam seu alinhamento com o que vem sendo apregoado pelos principais pesquisadores desse tema, em âmbito nacional, como é possível perceber nas palavras de Boso (2011):

\footnotetext{
Em tal sentido, os repositórios institucionais asseguram maior visibilidade e maior acesso às produções científicas, aumentando as possibilidades de pesquisas divulgadas serem citadas e reconhecidas nacional e internacionalmente, minimizando barreiras impostas aos sistemas tradicionais de publicação. (BOSO, 2011, p. 25).
}

Já as questões dez e onze, que faziam referência a aspectos técnicos, demonstraram a preocupação da Equipe com a necessidade da plataforma se comunicar com outros sistemas. Além de exporem o problema enfrentado na UFPel com relação a inconstância da conexão com a Internet e a falta de uma equipe de suporte técnico informático mais voltada às questões relacionadas à Gestão da Informação, com disponibilidade de tempo para se dedicar mais aos projetos com tal finalidade.

Por fim, analisando as questões seis e sete, que diziam respeito ao conteúdo do RI, observa-se que o anseio do grupo responsável é por uma plataforma que possibilite o livre acesso, sem qualquer tipo de restrição. Também foi possível constatar o interesse na construção de uma base de dados de textos completos, mesmo que o acesso nem sempre se dê ao inteiro teor do documento, pois, para fins de preservação digital, 
requer-se que o arquivamento seja sempre do documento completo e não somente de uma referência ou resumo. Nesse sentido, Sayão e Marcondes (2009) destacam que:

\begin{abstract}
A implantação de um repositório institucional é o reconhecimento de que as atividades intelectuais e acadêmicas das instituições de pesquisa e ensino estão crescentemente representadas, documentadas e compartilhadas em formato digital; e que uma das principais responsabilidades dessas instituições de conhecimento é exercitar a custódia sobre esses conteúdos no sentido de torná-los disponíveis para o acesso e para preservá-los por longo prazo. (SAYÃO; MARCONDES, 2009, p. 23).
\end{abstract}

Dessa forma, fica claro que as intenções da Equipe desta Universidade estão afinadas com uma das finalidades e aplicações dos RI.

\title{
4.2 Formulário
}

Outras informações pertinentes ao resultado deste estudo foram obtidas com a utilização do formulário, o qual passará a ser analisado neste momento.

Entre as preocupações que o Comitê Gestor transpareceu, durante a aplicação do questionário, estava a questão dos requisitos tecnológicos necessários para a implantação e o desenvolvimento do RI. Sendo assim, o primeiro tópico do formulário se prestou a tal investigação. Os requisitos tecnológicos apresentados na obra analisada são os mesmos contemplados no kit tecnológico fornecido pelo IBICT. Além desses, o livro orienta que sejam previstas condições que garantam a preservação digital dos documentos armazenados, através do planejamento e dimensionamento adequado de um servidor de dados, bem como de um programa de backup freqüente e regular.

A preservação digital foi também tema do segundo tópico, pois foi apontada como parte da finalidade que o RI teria para a Instituição. Essa é citada também como uma das principais funções dos repositórios pelo livro em questão. Devido à relevância dessa função, o livro orienta sobre a elaboração de política voltada à preservação que estabeleça em detalhes como ela ocorrerá.

Nos tópicos três e quatro foram observadas as possibilidades de gestão centralizada e povoamento descentralizado, pois essas características foram também destacas pelo membro do Comitê. Referente a essas funcionalidades, constatou-se que ambas são possíveis e indicadas para aumentar a produtividade e o desempenho dos 
responsáveis pela inserção de dados no sistema de informação, pois através do povoamento descentralizado pode-se autorizar que o próprio autor, ou uma pessoa indicada por ele, realize o autoarquivamento. Ao passo que, a gestão centralizada permite a revisão dos metadados (possibilitando sua padronização) e do conteúdo arquivado, sob o ponto de vista dos direitos autorais, para evitar que a instituição incorra em qualquer problema legal.

Os tópicos cinco e oito eram voltados às informações de apoio administrativo que se pode obter a partir do RI. No item cinco explorou-se a questão da produção docente, buscando saber se existia uma forma de controle do que cada professor produz e deposita no repositório. Já no item oito se desejava saber sobre a possibilidade de se obter dados estatísticos de acesso e uso (download) dos trabalhos arquivados. Essas duas necessidades podem ser supridas com as ferramentas de estatística e de geração de relatórios do RI, que emite relatórios distintos a partir de diferentes filtros, muito úteis à gestão da informação institucional. Corroborando com tal afirmação, Boso (2011) destaca que as estatísticas são especialmente relevantes para os gestores dos repositórios, auxiliando-os no processo de verificação do uso dos documentos depositados, além de estabelecer métodos científicos de coleta, classificação, apresentação e interpretação dos dados observados. Ao que Kuramoto (2009) acrescenta:

\begin{abstract}
A experiência mostra que com o tempo os próprios autores (pesquisadores) se convencem dos benefícios e da importância do depósito de sua produção científica e voluntariamente passam a ser defensores do RI. Isto acontece devido às estatísticas que são produzidas a partir do uso dos repositórios indicando a quantidade de downloads dos seus artigos depositados no RI. Estudos mostram que o depósito da produção científica tende a dar maior visibilidade aos autores e às universidades. $\mathrm{O}$ resultado disto é que as universidades que mantêm o seu repositório atualizado ganham maior poder de competitividade e os autores tendem a ser mais citados. (KURAMOTO, 2009, p. 216).
\end{abstract}

Dessa maneira, os teóricos do assunto endossam a preocupação do referido Comitê, ao passo que demonstram a fundamentação e real importância de se dispor de dados estatísticos, que podem ser obtidos através da plataforma dos repositórios.

O item seis tinha relação com a necessidade da UFPel de dar maior visibilidade a sua produção intelectual. Por isso procurava saber como o RI poderia auxiliar na divulgação dessa produção. Com a utilização de metadados, padrões de descrição e do 
protocolo OAI-PMH, os documentos arquivados no RI podem ser recuperados por buscadores de ampla utilização, sendo facilmente encontrados através de buscas simples na Web. Essa é a principal forma de divulgação do conteúdo dos repositórios, devido ao seu excelente resultado e à relação íntima que possui com o modo de desenvolvimento e funcionamento desses.

A questão da importação de dados, abordada no item sete, é, a princípio, prevista pelos softwares de repositórios. Entretanto, Leite (2009) salienta que podem existir algumas limitações nesse sentido, até mesmo devido ao outro software, de onde se quer importar dados. Os softwares de gestão de acervos costumam possibilitar tal comunicação de dados, mesmo que mediante alguma adaptação feita por um profissional da área de Tecnologia da Informação (TI). Já a plataforma Lattes, por exemplo, requer procedimentos burocráticos para liberação de processos dessa ordem.

A limitação da disponibilidade de trabalhos, ou parte desses, conta com uma ferramenta muito importante na plataforma dos repositórios - o embargo (permite o arquivamento do documento sem possibilitar sua visualização). Essa ferramenta, bem como as licenças Creative Commons - utilizadas para informa ao usuário qual uso pode ser feito de determinado documento - são mais exploradas no item nove do formulário.

A possibilidade de customização - configuração da interface de acordo com o perfil da instituição - ficou evidente através da análise feita no tópico dez. Tal possibilidade se estende de aspectos técnicos a visuais, com o intuito de dar maior individualidade ao RI.

\section{CONSIDERAÇÕES FINAIS}

Este estudo, pautado por dois instrumentos de coleta de dados - questionário e formulário - perseguiu com êxito seu objetivo: verificar a adequação do repositório institucional às necessidades da UFPel, no que diz respeito à gestão da produção intelectual do seu corpo docente. Para tanto, trouxe à tona importantes reflexões, que servirão de base para apoiar o processo decisório do Comitê Gestor responsável pela gestão da produção intelectual da UFPel.

Diante do grande número de trabalhos produzidos e acumulados pela comunidade acadêmica da UFPel, esta, representada pelo Comitê Gestor da Produção 
Intelectual,vem há algum tempo sentindo a necessidade de desenvolver um projeto com o objetivo de: reunir, preservar, dar amplo acesso e divulgar os trabalhos de pesquisa de sua comunidade docente.

Em 2009, o IBICT lançou um edital de incentivo à criação e ao desenvolvimento de RI, por parte das instituições públicas de ensino e pesquisa. Buscando fomentar iniciativas nesse sentido, disponibilizou um kit tecnológico a essas instituições, mediante a elaboração de projetos de criação de RI. Nessa ocasião, um docente da UFPel, vislumbrando a possibilidade de dar maior visibilidade a sua produção científica, elaborou um projeto solicitando o kit para a Universidade, ao que foi contemplado. No entanto, como essa não foi uma iniciativa administrativa da Instituição, ainda se fazia necessário avaliar se o RI se constituía como a melhor alternativa para suprir as necessidades identificadas pela Equipe responsável pela Gestão da Informação da UFPel.

Para sanar essa dúvida - sobre a adequação da plataforma do RI e suas características às necessidades da UFPel - faziam-se necessárias duas análises distintas: uma sobre às expectativas do Comitê Gestor da Produção Intelectual da Universidade e outra sobre as características e ferramentas disponíveis na plataforma do repositório disponibilizada, através do kit tecnológico, pelo IBICT. De posse dessas duas análises e através da comparação entre os anseios do Comitê e as características e funcionalidades do RI, pode-se atingir o objetivo deste estudo.

Partindo do ponto em que os instrumentos de pesquisa já haviam sido aplicados e as informação coletadas, procedeu-se o cruzamento dos dados e a análise conclusiva, chegando-se ao seguinte resultado. Os RI foram desenvolvidos tendo em vista problemas recorrentes em instituições acadêmicas e científicas de várias partes do mundo, no tocante à gestão da produção intelectual, além da preocupação central com o livre acesso à informação científica. Sendo assim, como já era esperado, a plataforma disponibilizada pelo IBICT, através do kit, apresenta funcionalidades importantes para a Gestão da Informação, que servem de solução a grande parte das necessidades levantadas pelo Comitê Gestor da Produção Intelectual da UFPel.

Portanto, chega-se a conclusão que o RI atende adequadamente às necessidades da UFPel, no que diz respeito à gestão da produção intelectual. No entanto, para garantir o sucesso dessa iniciativa se faz necessário: um planejamento adequado; uma normativa 
que institua e regulamente o funcionamento do repositório dentro da Instituição; uma boa campanha de divulgação e sensibilização dentro da Universidade, orientando sobre a utilização do RI e esclarecendo sobre seus benefícios e; um respaldo institucional que viabilize medidas visando garantir o bom funcionamento da conexão com a Internet e o devido suporte da equipe de Tecnologia da Informação (TI) para adaptações, customizações e conversões que se façam necessárias.

\section{REFERÊNCIAS}

BOSO, Augiza Karla. Repositórios de instituições federais de ensino superior e suas políticas: análise sob o aspecto das fontes informacionais. 2011. 140 f. Dissertação (Mestrado em Ciência da Informação) - Universidade Federal de Santa Catarina, Centro de Ciências da Educação. Programa de Pós-Graduação em Ciência da Informação, Florianópolis, SC, 2011. Disponível em: 〈http://pgcin.paginas.ufsc.br/files/2010/10/BOSO-Augiza-Karla.pdf>. Acesso em: 14 jun. 2012.

COSTA, Sely Maria de Sousa. Filosofia aberta, modelos de negócios e agências de fomento: elementos essenciais a uma discussão sobre o acesso aberto à informação científica. Ci. Inf., Brasília, v. 35, n. 2, p. 39-50, maio/ago. 2006. Disponível em: <http://revista.ibict.br/index.php/ciinf/article/view/827>. Acesso em: 21 nov. 2009.

CROW, R. The case for institutional repositories: A SPARC Position Paper. Washington, DC: Scholarly Publishing \& Academic Resources Coalition, 2002. Disponível em: 〈http://www.arl.org/sparc/bm doc/ir_final_release_102.pdf >. Acesso em: 22 nov. 2009.

KURAMOTO, Hélio. Informação científica: proposta de um novo modelo para o Brasil. Ci. Inf., Brasília, DF, v. 35, n. 2, p. 91-102, maio/ago. 2006. Disponível em: <http://revista.ibict.br/index.php/ciinf/article/viewArticle/831 > . Acesso em: 21 nov. 2009.

KURAMOTO, Hélio. Repositórios institucionais: políticas e mandatos. In: SAYÃO, Luis Fernando et al. (Org.). Implantação e gestão de repositórios institucionais: políticas, memória, livre acesso e preservação. Salvador: EDUFBA, 2009. p. 203 - 217.

LEITE, Fernando César Lima. Como gerenciar e ampliar a visibilidade da informação científica brasileira: repositórios institucionais de acesso aberto. Brasília, DF: IBICT, 2009.

LEITE, Fernando César Lima. Diretrizes para a construção de repositórios institucionais de acesso aberto à informação científica. In: SEMINÁRIO NACIONAL DE BIBLIOTECAS UNIVERSITÁRIAS, 15., 2008, [São Paulo]. Tópico temático... [São 
Paulo]: IBICT, 2008. Disponível em:

$<$ http://eprints.rclis.org/15188/1/Como_criar_RI_vers\%C3\%A3o_SNBU.pdf $>$. Acesso em: 15 abr. 2012.

LYNCH, Clifford A. Institutional repositories: essential infrastructure for scholarship in the Digital Age. ARL, n. 226, p. 1-7, Feb. 2003. Disponível em:

<http://www.arl.org/resources/pubs/br/br226/br226ir.shtml>. Acesso em: 23 nov. 2009.

MARCONDES, Carlos Henrique; SAYÃO, Luis Fernando. Documentos digitais e novas formas de cooperação entre sistemas de informação em C\&T. Ci. Inf., Brasília, DF, v. 31, n. 3, p. 42-54, set./dez. 2002. Disponível em:

<http://dici.ibict.br/archive/00000103/>. Acesso em: 21 nov. 2009.

MORAES, Rosane P. T. de; MARCONDES, Carlos H. O livre acesso e os arquivos abertos na comunicação científica. Diálogo Científico, Brasília, DF, v. 1150, 2006. Disponível em: 〈http://dici.ibict.br/archive/00001150/>. Acesso em: 21 nov. 2009.

PAVANI, Ana. Arquivos abertos, a OAI e o OAI-PMH. In: ORGANIZACIÓN DE LAS NACIONES UNIDAS PARA LA EDUCACIÓN, LA CIENCIA E LA CULTURA (Montevideo). Curso Mercosur sobre Construcción de Bibliotecas Digitales. Montevideo, 2005. 32 p. Disponível em:

$<$ http://www.unesco.org.uy/informatica/publicaciones/bibliotecasdigitales2005/pavaniar quivo sabertos.pdf>. Acesso em: 21 nov. 2009.

SAYÃO, Luis Fernando; MARCONDES, Carlos Henrique. Software livres para repositorios institucionais: alguns subsídios para a seleção. In: SAYÃO, Luis Fernando et al. (Orgs). Implantação e gestão de repositórios institucionais: políticas, memória, livre acesso e preservação. Salvador: EDUFBA, 2009. p. 23-54.

THE OPEN Archives Initiative Protocol for Metadata Harvesting. [S.1.]: The OAI Executive; From the OAI Technical Committee, 2008. Disponível em: <http://www.openarchives.org/OAI/2.0/openarchivesprotocol.htm>. Acesso em: 6 jan. 2010.

TRISKA, Ricardo; CAFÉ, Lígia. Arquivos abertos: subprojeto da biblioteca digital brasileira. Ci. Inf., Brasília, DF, v. 30, n. 3, p. 92-96, set./dez. 2001. Disponível em: <http://revista.ibict.br/index.php/ciinf/article/view/207/184>. Acesso em: 15 abr. 2012.

UNIVERSIDADE FEDERAL DE PELOTAS. UFPel: 30 anos. Pelotas: Ed. UFPel, 1999. $129 \mathrm{p}$.

UNIVERSIDADE FEDERAL DE PELOTAS. In: WIKIPÉDIA a enciclopédia livre. 2012. Disponível em: 〈http://pt.wikipedia.org/wiki/Universidade_Federal_de_Pelotas〉. Acesso em: 8 maio 2012 .

VIANA, Cassandra Lúcia de Maya; MÁRDERO ARELLANO, Miguel Angel. Repositórios institucionais baseados em DSpace e EPrints e sua viabilidade nas 
instituições acadêmico-científicas. In: SEMINÁRIO NACIONAL DE BIBLIOTECAS UNIVERSITÁRIAS, 14., Salvador, 2006. Anais... Salvador: [IBICT], 2006. Disponível em: 〈http://dici.ibict.br/archive/00001087/>. Acesso em: 21 nov. 2009.

VIANA, Cassandra Lúcia de Maya; MÁRDERO ARELLANO, Miguel Angel; SHINTAKU, M. Repositórios institucionais em ciência e tecnologia: uma experiência de customização do Dspace. In: SIMPOSIO INTERNACIONAL DE BIBLIOTECAS DIGITAIS, 3., 2005, São Paulo. Anais... São Paulo: Universidade de São Paulo: Universidade Estadual Paulista, 2005. Disponível em: <http://hdl.handle.net/10760/7168>. Acesso em: 14 jun. 2012.

WEITZEL, Simone R. Iniciativa de arquivos abertos como nova forma de comunicação científica. In: SEMINÁRIO INTERNACIONAL LATINO-AMERICANO DE PESQUISA EM COMUNICAÇÃO, 3., 2005, São Paulo. Anais eletrônicos... La Paz: Asociación Latinoamericana de Investigaciones de la Comunicación ALAIC, 2005. Disponível em: 〈http://hdl.handle.net/1904/18529>. Acesso em: 21 nov. 2009.

\section{ANEXO A - QUESTIONÁRIO}

Este Instrumento de Coleta de Dados tem o objetivo de conhecer as características que um repositório institucional deve apresentar para que desempenhe adequadamente a gestão da produção intelectual da Universidade Federal de Pelotas (UFPel).

1 Qual a principal finalidade do RI para a Instituição?

2 Como se dá a inserção de dados no RI

( ) Pela equipe de criação e gestão, tendo todos os membros as mesmas permissões

( ) Por apenas um dos membros da equipe de criação

( ) Pela Central do Núcleo de Bibliotecas

() Cada unidade de ensino da UFPel terá responsabilidade por sua "comunidade" dentro do RI

3 Quem tem permissão para fazer alterações estruturais no RI?

4 Quem poderá povoar o repositório, ou seja, depositar artigos, capítulos de livros ou trabalhos publicados em eventos no RI?

5 Como o conhecimento deve ser organizado, por unidade acadêmica, por exemplo?

6 Como deve ser o acesso ao conteúdo do RI

() acesso livre sem nenhuma restrição

( ) com restrições mediante login e senha 
7 O RI atuará como uma base de dados de

() texto completo

( ) referências

( ) resumo

( ) misto

8 Como será a obrigatoriedade de depósito por parte dospesquisadores da UFPel

( ) deverá depositar toda a produção, logo após a publicação. Salvo em caso de comprometimento com editora que restrinja o depósito. Nesse caso terá o prazo estipulado em contrato com o publicador para efetuar o depósito. Poderá também, nesse caso, depositar de forma oculta, visando apenas à preservação digital.

( ) terá que depositar apenas conteúdo publicado em meios de acesso livres.

( ) poderá realizar o depósito quando quiser, sem ter nenhuma obrigatoriedade.

$9 \mathrm{O}$ (s) principal(is) objetivo(s) a ser(em) atingidos através do RI é/são

( ) registrar e preservar a memória intelectual da Universidade.

( ) dar acesso amplo e irrestrito à produção intelectual à comunidade.

( ) ampliar a visibilidade da produção científica da Universidade.

( ) ampliar os serviços oferecidos pela biblioteca.

( ) otimizar a gestão da informação produzida na UFPel.

() reunir e disponibilizar os acervos digitais dispersos.

( ) contribuir para aumentar o impacto das pesquisas realizadas na Instituição.

( ) Avaliar o corpo docente sobre sua produção científica.

10 Existem limitações no que se refere ao suporte tecnológico (computadores, programas - compatibilidade/incompatibilidade, Internet)?

11 Há dúvidas, por parte desta equipe, sobre a viabilidade técnica do RI suprir alguma necessidade da UFPel?

12 Qual será o método utilizado para fazer com que os pesquisadores efetivamente realizem o auto-arquivamento no RI? 


\section{ANEXO B - FORMULÁRIO DE COLETA DE DADOS SOBRE REPOSITÓRIO INSTITUCIONAL}

Este formulário foi elaborado com base nas dúvidas identificadas em questionário respondido pelo membro do Comitê Gestor responsável pela implantação do RI da UFPel (ou de solução equivalente, julgada mais adequada) onde o presente trabalho se desenvolveu. As respostas a esses questionamentos foram buscadas na obra de Fernando César Lima Leite, editada pelo IBICT, a qual se constitui como uma espécie de manual de desenvolvimento e manutenção de RI. Vale lembrar ainda que a publicação dessa obra e a doação do kit tecnológico integram um conjunto de estratégias do IBICT para incentivar a adoção de RI pelas instituições federais de pesquisa e ensino.

1 Requisitos tecnológicos

2 Preservação digital da produção intelectual

3 Gestão centralizada

4 Povoamento descentralizado

5 Verificação da produção de cada docente para fins de avaliação

6 Ferramentas que auxiliem na divulgação do conteúdo depositado no RI

7 Importação de dados

8 Estatísticas de acesso, download

9 Disponibilização/limitação do texto completo - embargo e licenças Creative Commons

10 Nível possível de alteração (customização) do RI da Instituição tendo como base o Kit tecnológico recebido do IBICT

\section{Como citar este documento:}

CARVALHO, Catarina de Quevedo Prestes de; CARVALHO, Rodrigo Aquino de. Repositório institucional como alternativa à gestão da produção intelectual da universidade federal de pelotas - ufpel. Rev. digit. bibliotecon. cienc. inf., Campinas, SP, v.12, n.2, p.81-101, maio/ago. 2014. ISSN 1678-765X. Disponível em: <http://www.sbu.unicamp.br/seer/ojs/index.php/rbci>. Acesso em: 